\title{
Effect of methanol content in commercial formaldehyde solutions on the porosity of RF carbon xerogels
}

\author{
Isabel D. Alonso-Buenaposada, Natalia Rey-Raap, Esther G. Calvo, J. Angel \\ Menéndez, Ana Arenillas* \\ Instituto Nacional del Carbón, CSIC, Apartado 73, 33080 Oviedo, Spain
}

\begin{abstract}
Methanol is used commercially as a stabilizer in solutions of formaldehyde to prevent its precipitation. However, the methanol content of commercially available formaldehyde solutions differs from one supplier to another. The $\mathrm{pH}$, dilution and $\mathrm{R} / \mathrm{F}$ ratio have been demonstrated to be interdependent variables that can be manipulated to tailor the porous properties of RF carbon xerogels. This work considers the methanol contained in formaldehyde solutions as a new variable to be studied in conjunction with those just mentioned. For the purpose of this study, the influence of methanol on the final porous properties of RF carbon xerogels has been evaluated. It was found that carbon xerogels synthesized using formaldehyde solutions with lower concentrations of methanol showed a higher total pore volume and pore size, and in turn, a lower density and a greater porosity. The porosity of RF carbon xerogels could therefore be radically modified depending on the commercial formaldehyde solution used for their synthesis.
\end{abstract}

Keywords: carbon xerogel, formaldehyde, methanol, controlled porosity 


\section{Introduction}

Carbon gels are nanoporous materials obtained by the polymerization of hydroxylated benzenes and aldehydes in the presence of a solvent following Pekala's method [1]. Most carbon gels presented in the literature are synthesized using resorcinol and formaldehyde as precursors and water as solvent [2-5], although other precursors and reaction media can be used [6-9].

The process follows four main steps from the initial mixture of precursors to the final carbon gel [10]. First of all, polymerization and gelation take place, causing the solution to turn gradually into a solid state. Then, an ageing step generates crosslinking reactions that result in a stable polymeric structure. Next, the solvent is removed in a drying step. Finally, the dry material is subjected to high temperature treatment to produce the carbon gel.

The drying step can be performed by one of three different methods, each of which generates different properties in the final gel: supercritical drying, freeze-drying and evaporative drying. These give rise to aerogels, cryogels and xerogels, respectively [5, 11-16]. In this particular study, microwave radiation was used as heating source from the beginning to the end of the process, i.e. for accelerating the polymerization and crosslinking reactions, and also for the evaporative drying [17, 18]. This has been demonstrated to be a cost-effective process since it offers the possibility of synthesizing carbon gels on a large scale via a simple and fast procedure to yield very competitive and highly valued materials [17-22].

Over the last ten years, carbon xerogels have emerged as materials with a great added value owing to the fact that their porosity can be controlled and designed by selecting 
the appropriate synthesis variables, both physical (i.e. temperature, time of synthesis, etc.) $[2,19]$ and chemical (i.e. $\mathrm{pH}$, dilution, ratio $\mathrm{R} / \mathrm{F}$, etc) [23-26]. In addition, it has been demonstrated that all these variables are interdependent, making it necessary to study several variables at the same time, for which the application of statistical programs and a global assessment of the results are required.

Methanol is used commercially as a stabilizer in formaldehyde solutions, and generates hemiacetal/acetal compounds which prevent the precipitation of the formaldehyde. The study of the influence of the proportion of methanol present in commercial formaldehyde solutions has attracted a great deal of attention owing to the fact that these solutions differ greatly in methanol content from one supplier to another. As an example, Table 1 shows different chemical suppliers and the percentages of methanol in their commercial formaldehyde solutions. It can be seen that the concentrations of methanol may differ substantially. It is well known that the physical and chemical properties of water and methanol also differ (i.e. dielectric constant, boiling point, surface tension, etc.) [27], and accordingly may have an influence in certain stages of the synthesis, such as the polymerization or drying steps. Indeed, RF gels synthesized with methanol as solvent have already been reported in the bibliography, and these carbon gels exhibit quite different properties to those synthesized in water [10, 28, 29].

Thus, the proportion of methanol in the formaldehyde solution is believed to affect the final porous properties of the RF xerogel. Accordingly, the aim of this work is to assess the influence that methanol contained in commercial formaldehyde solutions has on the final porous properties of RF carbon xerogels.

\section{Experimental}




\subsection{Synthesis of carbon xerogels}

Carbon xerogels were synthesized by the polymerization of resorcinol (R) and formaldehyde (F), using deionized water as solvent and $\mathrm{NaOH}$ as catalyst of the reaction. First of all, resorcinol (Indspec, 99.6 wt. \%) was dissolved in deionized water in an unsealed glass beaker under magnetic stirring until completely dissolved. In another beaker, formaldehyde (Química S.A.U., 37 wt. \% formaldehyde, 0.6 wt. \% methanol, 62.4 wt. \% water) was mixed with methanol (AnalaR Normapur, $99.9 \%$ ) under stirring in order to obtain formaldehyde solutions with different proportions of stabilizer. Afterwards, both solutions were mixed and stirred until a homogeneous solution was obtained. Then, two different $\mathrm{NaOH}$ solutions were used in order to achieve the desired $\mathrm{pH}$ : a $\mathrm{NaOH} 5 \mathrm{M}$ solution prepared from solid $\mathrm{NaOH}$ (AnalaR Normapur, $99.9 \%$ ) and a $\mathrm{NaOH} \mathrm{0.1} \mathrm{M} \mathrm{solution} \mathrm{(Titripac,} \mathrm{Merck).}$

The proportions of each reagent depend on the dilution ratio (D), the $\mathrm{R} / \mathrm{F}$ ratio, the $\mathrm{pH}$ and the percentage of methanol selected for each experiment. The dilution ratio is defined as the molar ratio of the total solvent to the reactants. Total solvent refers to the water and methanol contained in the formaldehyde solution and the amount of deionized water and methanol added, whilst reactants refers only to the resorcinol and formaldehyde.

In the present work, dilutions between 5 and $8, \mathrm{R} / \mathrm{F}$ ratios from 0.3 to $0.7, \mathrm{pH}$ values between 4 ( $\mathrm{pH}$ with no catalyst added) and 7, and percentages of methanol from 0.6 (already contained in the commercial formaldehyde solution employed) to 12.5 , were used. These limits were selected taking into account other studies found in the bibliography [23]. The range of the methanol percentages was selected from the different commercial formaldehyde solutions available (see Table 1). 
Each precursor solution was placed in a microwave oven at $85^{\circ} \mathrm{C}$ for about 3 hours for the gelating and ageing steps, according to the operating conditions described elsewhere $[18,23,24]$. The polymer was then dried by microwave heating until a mass loss of over 50 wt. \% was recorded, giving rise to the organic gel. Next, The organic gel was carbonised in a tubular reactor for $2 \mathrm{~h}$ at $700^{\circ} \mathrm{C}$ under a $\mathrm{N}_{2}$ flow $\left(150 \mathrm{~mL} \mathrm{~min}^{-1}\right)$ to yield the desired carbon gel end product.

The sample nomenclature selected throughout this study is as follows: "CX-pH-D-R/FM" where the $C X$ is the abbreviation for the carbon xerogels and the $p H, D, R / F$ and $M$ are 4 numerical values corresponding to the $p H$ of the precursor solution, the dilution ratio, the $R / F$ molar ratio and the percentage of methanol contained in the formaldehyde solution, respectively.

\subsection{Sample characterization}

Sample particles of diameter $2-3 \mathrm{~mm}$ were previously outgassed at $120{ }^{\circ} \mathrm{C}$ and $0.1 \mathrm{mbar}$ overnight (Micromeritics VAcPrep 0.61) before being characterized. The porous properties of the carbon gel were analysed by means of different techniques: the mesomacroporosity was determined by mercury porosimetry (Micromeritics AutoPore IV),

while the microporosity was evaluated by nitrogen adsorption-desorption isotherm analysis at $-196{ }^{\circ} \mathrm{C}$ (Micromeritics Tristar 3020). Micrographs of the carbon xerogels were also obtained on a Zeiss DSM 942 scanning electron microscope.

\subsection{Experimental design}


As is well known, the final porous properties of carbon gels are affected by several variables which are interrelated $[12,18,23,24]$. Therefore, the selection of the variables for tailoring the final properties is crucial. The biggest challenge in this study was to ensure that most of the possible combinations of $\mathrm{pH}, \mathrm{D}, \mathrm{R} / \mathrm{F}$ and $\% \mathrm{MeOH}$ were covered, taking into account that this is a four-dimensional study and an exponential number of combinations of variables is possible for each experiment.

Accordingly, an experimental design of four variables was constructed based on Response Surface Methodology (RSM), using a Design Of Experiments (DOE) which allowed the largest possible number of combinations to be covered by the smallest possible number of experiments. A D-optimal design was applied to 146 experiments, from which a statistical model was obtained for the different responses of the system: mesopore volume, macropore volume, pore diameter, bulk density and porosity, etc. This experimental design was applied using Design-Expert 7®.

\section{Results and discussion:}

In order to present the large amount of results obtained in a clear manner, a sample (CX-6-5-0.3) obtained from a precursor solution with a $\mathrm{pH}$ of 6 , a dilution ratio of 5 and a $\mathrm{R} / \mathrm{F}$ molar ratio of 0.3 was taken as a reference. The $\mathrm{pH}$, dilution ratio and $\mathrm{R} / \mathrm{F}$ molar ratio were varied with respect to the reference sample. The other variables used were kept constant during the synthesis process. Every combination of variables was prepared using four different methanol concentrations (i.e. from 0.6 to $12.5 \mathrm{wt}$ \%). A selection of the resulting samples is presented in Table 2 . 
As can be seen, a decrease in the concentration of methanol leads to an increase in the total pore volume (up to $218 \%$ ), pore size (up to $400 \mathrm{~nm}$ ) and porosity (up to $64 \%$ ) and, as a consequence, to a decrease in density (up to $37 \%$ ). This strong influence is graphically shown in Figure 1. The corresponding variations for the reference samples are shown in Figure 1a, where it can be seen that the total pore volume increases as the concentration of methanol decreases.

The same trend is also observed for the different $\mathrm{pH}, \mathrm{R} / \mathrm{F}$ molar ratio and dilution ratios (Figures $1 \mathrm{~b}, 1 \mathrm{c}$ and $1 \mathrm{~d}$, respectively). However, the contribution of the mesopore and macropore volume to the total volume of pores is different as it depends on all the other chemical variables selected. Figure 1a shows mesoporous materials and, in this case, methanol only affects the volume of mesopores, since these samples do not have any macroporosity. However, Figure $1 \mathrm{~b}$ shows samples with different a $\mathrm{pH}$ (i.e. a precursor solution $\mathrm{pH}$ of 5). Here it can be seen that not only is the total pore volume three times larger when 0.6 wt. $\%$ of methanol is applied instead of 12.5 wt. $\%$, but also that the type of porosity has changed radically. In this case, the sample obtained with 0.6 wt. \% of methanol is a macroporous material, while that obtained with $12.5 \mathrm{wt}$. \% of methanol is mesoporous. These results show that a change in the proportion of methanol affects the porosity of the resulting material considerably.

Figure 1c displays samples where the R/F molar ratio has been increased with respect to the reference ones. In this case, the increase in pore volume obtained is not directly proportional to the decrease in methanol, since the increase, when the methanol decreases from 4 to $0.6 \mathrm{wt} . \%$ is higher than in the case of the other formulations (see Table 2). In Figure 1d samples with different dilution ratios are shown. As can be observed, the total pore volume increases only slightly with the decrease in methanol content, but the type of pores obtained changes drastically in that the material obtained 
is predominantly mesoporous when $12.5 \mathrm{wt}$. \% of methanol solution is used, but totally macroporous when 4 wt. \% of methanol is employed. It was not possible to synthesize carbon xerogels with 0.6 wt. \% of methanol under the conditions used in this study, since gelation did not take place, and the precursor solution remained in a sol state.

It is well known that the $\mathrm{pH}$ of the precursor solution has a strong effect on the porosity of carbon xerogels. Higher $\mathrm{pH}$ values enhance polymerization, leading to an increase in the number of clusters of lower size and as a consequence, a decrease in the pore size $[18,23,24,27,30,31]$. For this reason, in Figure 2a, which corresponds to samples obtained with a $\mathrm{pH}$ value of 6 , pore sizes are in the mesopore range (i.e. pores between 5 and $25 \mathrm{~nm}$, depending on the sample) whereas in Figure $2 \mathrm{~b}$, corresponding to samples with a $\mathrm{pH}$ of 5 , pores of hundreds of nm may develop. Therefore, as the $\mathrm{pH}$ of the precursor solution decreases, not only does the pore size increase but also the total pore volume. Moreover, in both cases, a decrease in the methanol concentration generates an increase in the pore size, which is much higher when a lower $\mathrm{pH}$ is used (i.e. the pore size can be increased from 22 to $420 \mathrm{~nm}$ merely by decreasing the methanol content of the sample obtained with a precursor solution $\mathrm{pH}$ of 5).

The $\mathrm{R} / \mathrm{F}$ molar ratio is considered another important variable for controlling the porosity of carbon xerogels. It has been demonstrated that, provided that the rest of the variables are kept constant, an excess of formaldehyde promotes the formation and growth of clusters and produces a greater number of interconnections [12, 24]. A decrease in the $\mathrm{R} / \mathrm{F}$ ratio displaces the reaction equilibrium to the products, giving rise to an increase in the rate of reaction and in the size of the clusters. The SEM micrographs in Figure 3 show the effect of this variable on the size of the clusters in the carbon xerogel and, in turn, on the final porosity. Thus, from the left to the right, it can be seen that an increase in the $\mathrm{R} / \mathrm{F}$ ratio leads to a decrease in the pore size and smaller clusters are formed. 
However, when the two rows corresponding to two different methanol concentrations are compared, it is observed that the effect of the methanol concentration is even greater than the influence of the $\mathrm{R} / \mathrm{F}$ ratio, as it is very difficult to distinguish differences between the $\mathrm{R} / \mathrm{F}$ ratios when $12.5 \mathrm{wt} . \%$ is the percentage of methanol used.

It has been demonstrated that chemical variables are interdependent [23, 24] and therefore, they must be studied simultaneously. As it is not possible to represent the variations and interdependence of four variables at the same time (i.e. $\mathrm{pH}$, dilution, $\mathrm{R} / \mathrm{F}$ ratio and percentage of methanol), Figure 4 only represents the combined effect of $\mathrm{pH}$ and dilution ratio on the mesopore volume for two different concentrations of methanol.

The dilution ratio used in the precursor solution affects the final porosity of carbon xerogels in that the greater the dilution ratio, the greater the distance between the clusters of polymers formed, leading to materials with wider pores $[23,24]$. The $\mathrm{R} / \mathrm{F}$ ratio was fixed at 0.3 for this study, as illustrated in Figure 4, because it has been observed to yield a large mesopore volume, not only in this work but also in previous published studies [24]. Figures $4 \mathrm{a}$ and $4 \mathrm{~b}$ show a three-dimensional surface plot with 0.6 and 12.5 wt. \% of methanol, respectively. Figure $4 \mathrm{c}$ and $4 \mathrm{~d}$ display the corresponding contour plots for the same methanol concentrations. In these graphs, it can again be observed that a decrease in the concentration of methanol produces an increase in the mesopore volume. Moreover, the maximum is displaced to a higher value of $\mathrm{pH}$ and the area corresponding to mesopore volume has been reduced.

It is not possible to synthesize samples with $0.6 \mathrm{wt}$ \% of methanol under the conditions of this work, when the $\mathrm{pH}$ and dilution are low, since the precursor solution would boil and the process would get out of control. Neither was it possible to synthesize samples with a low $\mathrm{pH}$ and a high dilution ratio because more than $3 \mathrm{~h}$ would be needed to reach 
the gelation point, making the process too costly. For this reason these areas are not represented on the graph (Figure 4d).

At some points on the plot, a decrease in pore volume seems to occur. However, the decrease observed is due to an enlargement of the pores, as a consequence of which some mesopores become macropores, leading to a decrease in the mesopore volume. This can also be observed in Figures $1 \mathrm{~b}$ and $1 \mathrm{~d}$, where the type of porosity has been drastically modified. In other regions of the graph in Figure 4, an increase in the mesopore volume is apparent, as occurs in Figures 1a and 1c.

All the samples were characterized by nitrogen adsorption in order to evaluate the microporosity developed in each case, besides the possible influence of methanol on this type of porosity. However, the microporosity of all the carbon xerogels remained more or less unchanged. Thus, all the samples in Table 1 present an similar BET surface area of ca. $600 \mathrm{~m}^{2} / \mathrm{g}$, and a mean micropore size of ca. $0.9 \mathrm{~nm}$. It can be inferred from this that the presence of methanol influences the size of the clusters and, in turn the meso-macroporosity of the carbon xerogels, though not the micropores that form inside the clusters.

The reason for the influence of methanol content on the final size of the clusters formed is related to the role that methanol plays in the stabilization of formaldehyde solutions. The oxygen in the carbonyl group from formaldehyde is protonated under acidic conditions, which leads to the formation of hemiacetal. However, a sufficient amount of methanol allows the reaction to form acetals, which are more stable compounds [28]. Therefore, an increase in the concentration of methanol results in the formation of more hemiacetals, leaving less formaldehyde available to participate in the sol-gel reaction. This result is somewhat similar to the effect produced by the decrease in the $\mathrm{R} / \mathrm{F}$ ratio in 
the formulation of carbon xerogels that leads to the formation of smaller clusters. Polymeric structures with small clusters give rise to small voids between clusters and hence to samples with smaller pores and a lower pore volume.

\section{Conclusions}

In this study it has been demonstrated that the concentration of methanol present in commercial formaldehyde solutions has a significant influence on the porosity of RF carbon xerogels synthesized in a microwave oven. Provided that the rest of the variables used in the synthesis process are kept constant, carbon xerogels synthesized with a lower concentration of methanol show a higher total pore volume and pore size and, as a consequence, a lower density and a higher porosity. This effect occurs to different degrees depending on the other variables used in the synthesis process. In some cases, the type of porosity changes dramatically and samples obtained by the same recipe may present meso or macroporosity depending on the concentration of methanol in the commercial formaldehyde solution. On the other hand microporosity does not seem to be influenced by the presence of methanol. In short, the concentration of methanol can be considered a highly useful novel chemical variable for tailoring the porosity of carbon xerogels for specific applications.

\section{Acknowledgements}

The financial support from the Ministerio de Economía y Competitividad of Spain MINECO (under Projects MAT2011-23733, IPT-2012-0689-420000 and CTQ201349433-EXP) is greatly acknowledged. 


\section{References}

1. Pekala, R., Organic aerogels from the polycondensation of resorcinol with formaldehyde. Journal of Materials Science, 1989. 24(9): p. 3221-3227.

2. Job, N., et al., Synthesis optimization of organic xerogels produced from convective air-drying of resorcinol-formaldehyde gels. Journal of NonCrystalline Solids, 2006. 352(1): p. 24-34.

3. Aguado-Serrano, J., et al., Surface and catalytic properties of acid metalcarbons prepared by the sol-gel method. Applied Surface Science, 2006. 252(17): p. 6075-6079.

4. Gun'ko, V.M., et al., Synthesis and characterization of resorcinol-formaldehyde resin chars doped by zinc oxide. Applied Surface Science, 2014. 303(0): p. 263271.

5. Léonard, A., et al., Evolution of mechanical properties and final textural properties of resorcinol-formaldehyde xerogels during ambient air drying. Journal of Non-Crystalline Solids, 2008. 354(10-11): p. 831-838.

6. Pérez-Caballero, F., et al., Preparation of carbon aerogels from 5methylresorcinol-formaldehyde gels. Microporous and Mesoporous Materials, 2008. 108(1-3): p. 230-236.

7. Szczurek, A., et al., The use of tannin to prepare carbon gels. Part II. Carbon cryogels. Carbon, 2011. 49(8): p. 2785-2794.

8. Szczurek, A., et al., The use of tannin to prepare carbon gels. Part I: Carbon aerogels. Carbon, 2011. 49(8): p. 2773-2784.

9. Grishechko, L.I., et al., New tannin-lignin aerogels. Industrial Crops and Products, 2013. 41(0): p. 347-355.

10. Al-Muhtaseb, S.A. and J.A. Ritter, Preparation and properties of resorcinolformaldehyde organic and carbon gels. Advanced Materials, 2003. 15(2): p. 101-114.

11. Kraiwattanawong, K., H. Tamon, and P. Praserthdam, Influence of solvent species used in solvent exchange for preparation of mesoporous carbon xerogels from resorcinol and formaldehyde via subcritical drying. Microporous and Mesoporous Materials, 2011. 138(1-3): p. 8-16.

12. ElKhatat, A.M. and S.A. Al-Muhtaseb, Advances in Tailoring ResorcinolFormaldehyde Organic and Carbon Gels. Advanced Materials, 2011. 23(26): p. 2887-2903.

13. Yamamoto, T., et al., Effect of drying method on mesoporosity of resorcinolformaldehyde drygel and carbon gel. Drying Technology, 2001. 19(7): p. 13191333.

14. Gallegos-Suárez, E., et al., On the micro- and mesoporosity of carbon aerogels and xerogels. The role of the drying conditions during the synthesis processes. Chemical Engineering Journal, 2012. 181-182(0): p. 851-855.

15. Szczurek, A., et al., Porosity of resorcinol-formaldehyde organic and carbon aerogels exchanged and dried with supercritical organic solvents. Materials Chemistry and Physics, 2011. 129(3): p. 1221-1232.

16. Liang, C., G. Sha, and S. Guo, Resorcinol-formaldehyde aerogels prepared by supercritical acetone drying. Journal of Non-Crystalline Solids, 2000. 271(1-2): p. 167-170. 
17. Calvo, E.G., et al., Microwave synthesis of micro-mesoporous activated carbon xerogels for high performance supercapacitors. Microporous and Mesoporous Materials, 2013. 168: p. 206-212.

18. Calvo, E.G., et al., Fast microwave-assisted synthesis of tailored mesoporous carbon xerogels. Journal of Colloid and Interface Science, 2011. 357(2): p. 541547.

19. Rey-Raap, N., J.A. Menéndez, and A. Arenillas, Optimization of the process variables in the microwave-induced synthesis of carbon xerogels. Journal of SolGel Science and Technology, 2014. 69(3): p. 488-497.

20. Tonanon, N., et al., Preparation of resorcinol formaldehyde (RF) carbon gels: Use of ultrasonic irradiation followed by microwave drying. Journal of NonCrystalline Solids, 2006. 352(52-54): p. 5683-5686.

21. Menéndez, J.A., et al., A microwave-based method for the synthesis of carbon xerogel spheres. Carbon, 2012. 50(10): p. 3555-3560.

22. Menéndez, J.A., et al., Microwave heating processes involving carbon materials. Fuel Processing Technology, 2010. 91(1): p. 1-8.

23. Rey-Raap, N., J. Angel Menéndez, and A. Arenillas, RF xerogels with tailored porosity over the entire nanoscale. Microporous and Mesoporous Materials, 2014. 195: p. 266-275.

24. Rey-Raap, N., J. Angel Menéndez, and A. Arenillas, Simultaneous adjustment of the main chemical variables to fine-tune the porosity of carbon xerogels. Carbon, 2014. 78: p. 490-499.

25. Moreno, A.H., et al., Carbonisation of resorcinol-formaldehyde organic xerogels: Effect of temperature, particle size and heating rate on the porosity of carbon xerogels. Journal of Analytical and Applied Pyrolysis, 2013. 100: p. 111116.

26. Al-Muhtaseb, S.A. and J.A. Ritter, Preparation and Properties of ResorcinolFormaldehyde Organic and Carbon Gels. Advanced Materials, 2003. 15(2): p. 101-114.

27. Carr, C. and J.A. Riddick, Physical properties of methanol-water system. Industrial \& Engineering Chemistry, 1951. 43(3): p. 692-696.

28. Zubizarreta, L., et al., Development of microporous carbon xerogels by controlling synthesis conditions. Journal of Non-Crystalline Solids, 2008. 354(10-11): p. 817-825.

29. Kiciński, W., M. Szala, and M. Nita, Structurally tailored carbon xerogels produced through a sol-gel process in a water-methanol-inorganic salt solution. Journal of Sol-Gel Science and Technology, 2011. 58(1): p. 102-113.

30. Durairaj, R.B., Resorcinol: chemistry, technology and applications. 2005: Springer Science \& Business Media.

31. Job, N., et al., Porous carbon xerogels with texture tailored by $\mathrm{pH}$ control during sol-gel process. Carbon, 2004. 42(3): p. 619-628. 
Table 1. Variation of the methanol content in different available commercial solutions of formaldehyde.

\begin{tabular}{|c|c|}
\hline SUPPLIER & Methanol concentration (wt. \%) \\
\hline Fernández Rapado & $<1.3$ \\
\hline Panreac & $9-14$ \\
\hline Solvech & $9-15$ \\
\hline Merck Chemicals & 10 \\
\hline Oxidal & $10-15$ \\
\hline Sigma-Aldrich & $10-15$ \\
\hline Spi-Chem & non specified \\
\hline
\end{tabular}


Table 2. Porosity parameters, derived from mercury porosimetry, of carbon xerogels obtained from 4 different recipes and in each case with 4 different methanol concentrations.

\begin{tabular}{|c|c|c|c|c|c|c|c|}
\hline & SAMPLE & $\begin{array}{c}\text { Vtot } \\
\left(\mathrm{cm}^{3} / \mathrm{g}\right)\end{array}$ & $\begin{array}{l}\text { Vmeso } \\
\left(\mathrm{cm}^{3} / \mathrm{g}\right)\end{array}$ & $\begin{array}{l}\text { Vmacro } \\
\left(\mathrm{cm}^{3} / \mathrm{g}\right)\end{array}$ & $\begin{array}{c}\text { Pore } \\
\text { diameter } \\
(\mathrm{nm})\end{array}$ & $\begin{array}{c}\text { Bulk } \\
\text { density } \\
\left(\mathrm{g} / \mathrm{cm}^{3}\right)\end{array}$ & $\begin{array}{c}\text { Porosity } \\
\text { (\%) }\end{array}$ \\
\hline \multirow{4}{*}{ Reference } & CX-6-5-0.3-12.5 & 0.53 & $\overline{0.53}$ & 0.00 & 12 & 0.74 & 38 \\
\hline & CX-6-5-0.3-8 & 0.69 & 0.69 & 0.00 & 14 & 0.70 & 47 \\
\hline & CX-6-5-0.3-4 & 0.78 & 0.78 & 0.00 & 15 & 0.64 & 49 \\
\hline & CX-6-5-0.3-0.6 & 0.89 & 0.89 & 0.00 & 18 & 0.59 & 52 \\
\hline \multirow{4}{*}{$\begin{array}{c}\text { Different } \\
\text { pH }\end{array}$} & $C X-5-5-0.3-12.5$ & $0.90^{-}$ & 0.88 & 0.02 & 22 & 0.50 & 44 \\
\hline & CX-5-5-0.3-8 & 1.37 & 0.82 & 0.54 & 46 & 0.46 & 64 \\
\hline & CX-5-5-0.3-4 & 1.94 & 0.11 & 1.83 & 101 & 0.35 & 67 \\
\hline & CX-5-5-0.3-0.6 & 2.55 & 0.03 & 2.52 & 420 & 0.30 & 72 \\
\hline \multirow{4}{*}{$\begin{array}{l}\text { Different } \\
\text { dilution }\end{array}$} & $\mathrm{CX}-6-8-0.3-12.5$ & 1.50 & 1.18 & 0.33 & $47^{-}$ & 0.43 & 63 \\
\hline & CX-6-8-0.3-8 & 1.53 & 0.14 & 1.39 & 65 & 0.43 & 64 \\
\hline & CX-6-8-0.3-4 & 1.58 & 0.04 & 1.55 & 124 & 0.42 & 64 \\
\hline & CX-6-8-0.3-0.6 & - & - & - & - & - & - \\
\hline \multirow{4}{*}{$\begin{array}{c}\text { Different } \\
\text { R/F }\end{array}$} & $\mathrm{CX}-6-5-0.7-12.5$ & 0.28 & 0.28 & 0.00 & 13 & 0.95 & 26 \\
\hline & CX-6-5-0.7-8 & 0.33 & 0.33 & 0.00 & 13 & 0.92 & 30 \\
\hline & CX-6-5-0.7-4 & 0.46 & 0.46 & 0.00 & 14 & 0.80 & 36 \\
\hline & CX-6-5-0.7-0.6 & 0.89 & 0.86 & 0.03 & 21 & 0.60 & 52 \\
\hline
\end{tabular}



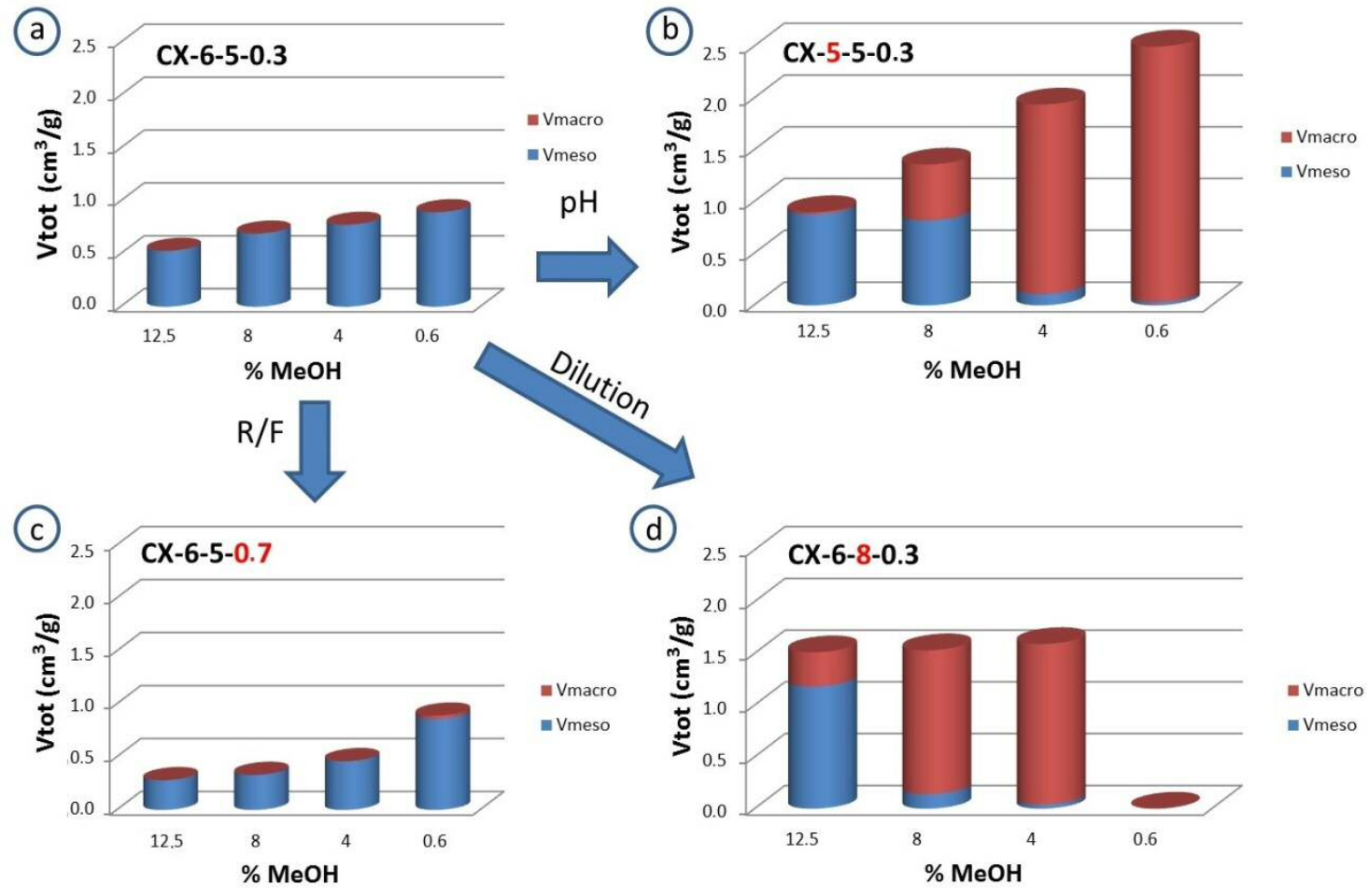

Figure 1. Influence of methanol concentration on the meso-macroporosity and total pore volume developed in carbon xerogels in combination with variation of the $\mathrm{pH}, \mathrm{R} / \mathrm{F}$ ratio and dilution of the precursor solution. 

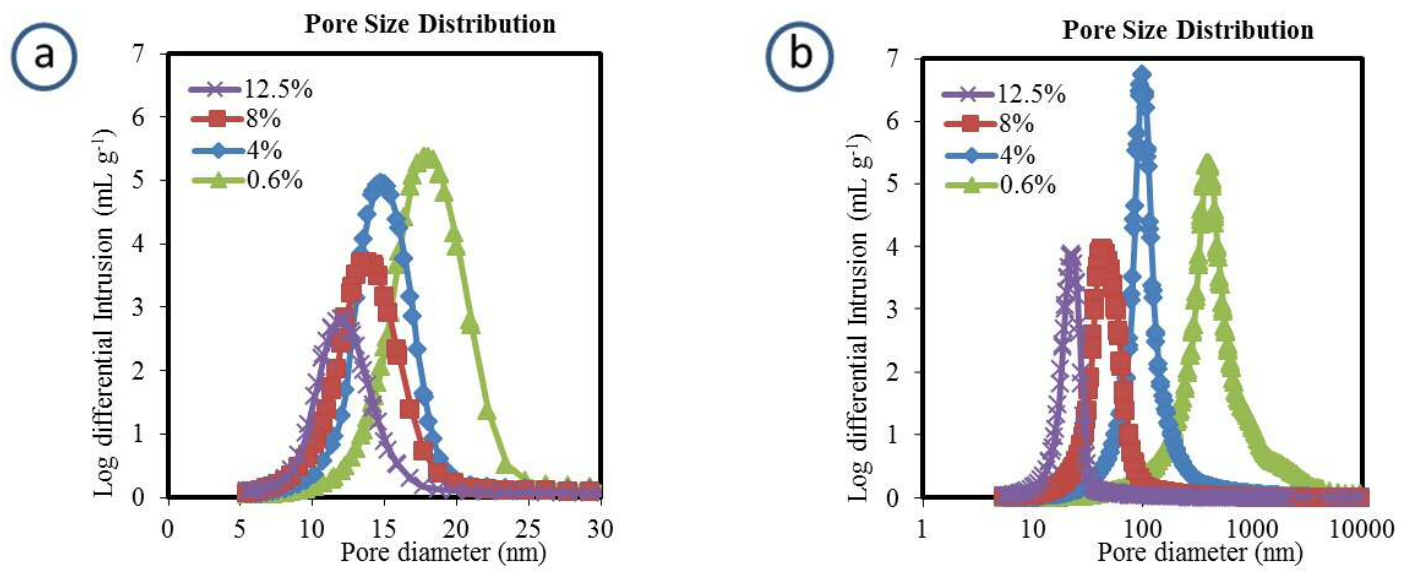

Figure 2. Variation of the pore size distribution of carbon xerogels due to different methanol proportions for two different precursor solution $\mathrm{pH}$ values: a) $\mathrm{pH}=6$ and $\mathrm{b}$ ) $\mathrm{pH}=5$. 


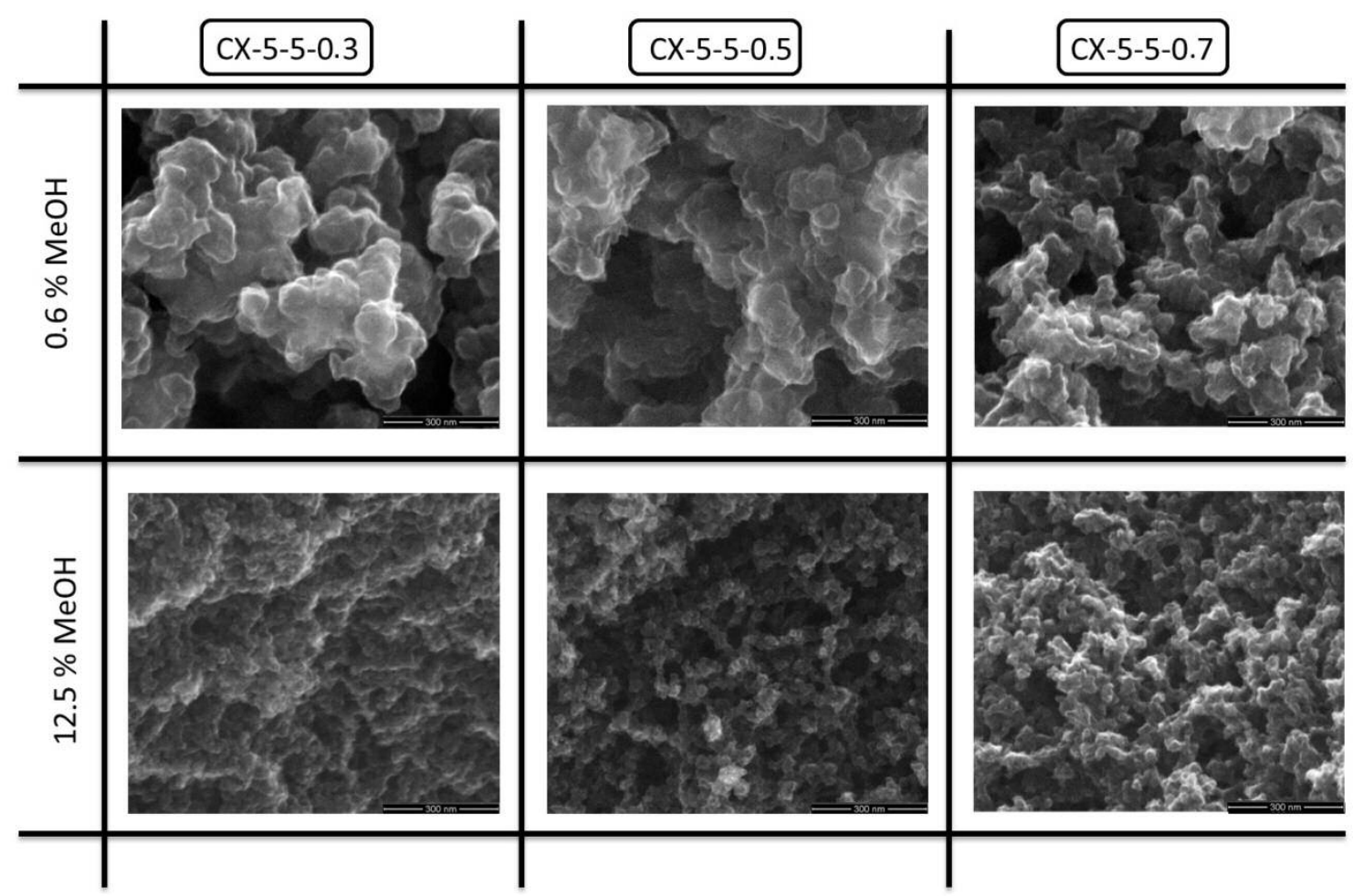

Figure 3. SEM images showing the influence of the $\mathrm{R} / \mathrm{F}$ molar ratio and methanol concentration in the formaldehyde solution on the size of the clusters formed and therefore on the final porosity of carbon xerogels. 
(a)

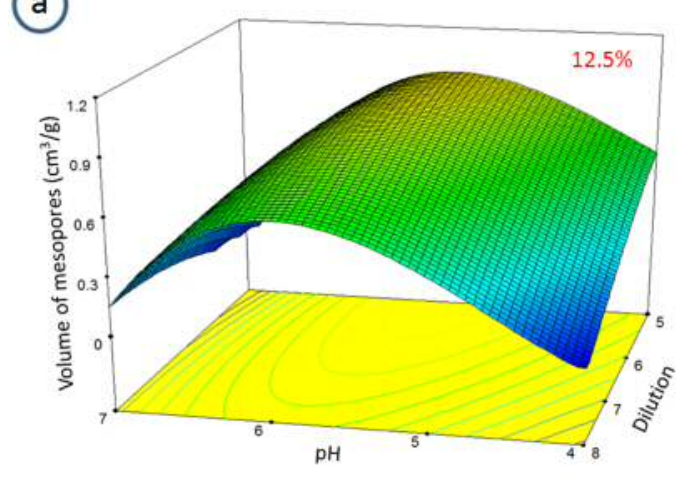

(b)
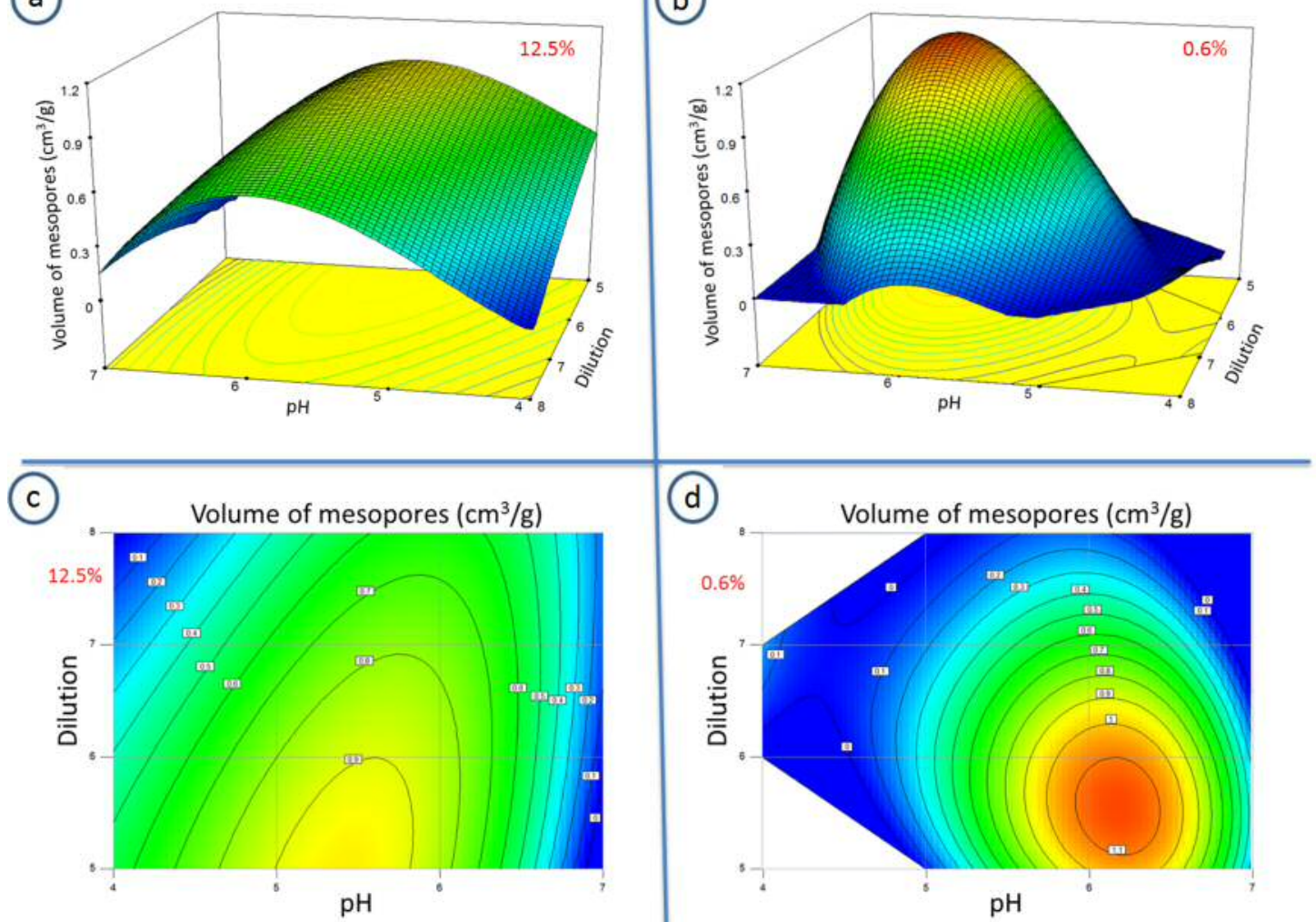

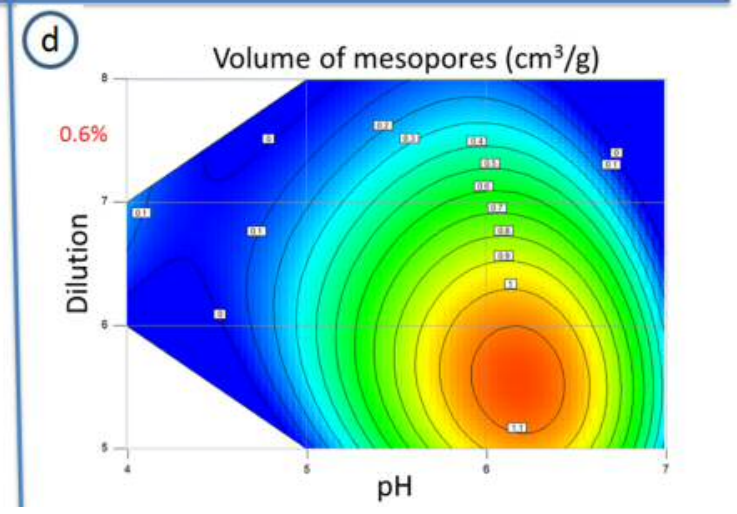

Figure 4. Three-dimensional surface plot and contour plot showing the combined effect of the dilution ratio and $\mathrm{pH}$ on the mesopore volume for two different methanol concentrations $(\mathrm{R} / \mathrm{F}$ ratio fixed at 0.3$)$. 